\title{
NGHIÊN CỬU BIẾN CHỨNG MẮT Ở BÊ̂NH NHÂN ĐÁI THÁO ĐƯờNG TẠI BỆNH VIỆN ĐA KHOA TRUNG TÂM TIỀN GIANG
}

Châu Mỹ Chi

DOI: $10.47122 / v j d e .2020 .43 .2$

Bệnh viện Đa khoa Trung tâm Tiền Giang

\begin{abstract}
Background: In Viet Nam, nearly $6 \%$ of the adult population have diabetes melitus (DM) and have high risk of losing their vision due to the complication from diabetic retinopathy (DR). Finding and treating diabetic retinopathy early can reduce the risk of blindness. Objective: To determine prevalence of eye diseases in diabetes mellitus attending Tien Giang Center General Hospital and to study the correlation between Eye diseases in diabetes and risk factors. Method: Weperformcross-sectional study on 111 patients with diabetes mellitus at Tien Giang Center General Hospital. All the diabetics underwent test The screening diabetic retinopathyby using Canon EOS 60Da. Result: The prevalence of eye disease in diabetes was $32.43 \%$, cataract: $11.71 \%$; diabetic retinopathy: $23.42 \%$, R1M0: $14.41 \%$, R1M1: $2.7 \%$, R2M0: 0.9\%, R2M1: $1.8 \%$, R3M1 $0.9 \%$. Eye diseases in diabetes were significantly associated with duration of diabetes, sex, hypertension, glycemie and chronic kidney disease. Conclusions: As retinopathy can cause blindness, it is very important that it is identified and treated as early as possible. To prevent diabetic eye disease, or to keep it from getting worse, manage your diabetes ABCs: your A1c, blood pressure, and cholesterol; and quit smoking if you smoke.
\end{abstract}

\section{TÓM TẮT}

Co sở lý luận: Tại Việt Nam, gần $6 \%$ người lớn tuổi mắc bệnh đái tháo đường và có nguy cơ mất thị lực do các biến chứng đáy mắt của bệnh lí Võng mạc đái tháo đường (VMĐTĐ). Phát hiện sớm và điều trị kịp thời võng mạc đái tháo đường có thể làm giảm mất thị lực. Mục tiêu: Xác định tỉ lệ biến chứng mắt trên bệnh nhân đái tháo đường tại bệnh viện Đa khoa Trung tâm Tiền Giang và tìm mối liên quan giữa biến chứng mắt và một số yếu tố nguy cơ. Phương pháp: Nghiên cứu cắt ngang mô tả bao gồm 111 bệnh nhân đái tháo đường tại bệnh viện Đa khoa Trung tâm Tiền Giang. Tất cả bệnh nhân được sàng lọc bệnh võng mạc bằng máy Canon EOS 60Da. Kết quả: Tỷ lệ bệnh mắt đái tháo đường chiếm $32,43 \%$. Trong đó đục thủy tinh thể là $11,71 \%$; bệnh võng mạc đái tháo đường 23,42\%, R1M0 là 14,41\%, R1M1: $2,7 \%$, R2M0:0,9\%, R2M1: 1,8\%, R3M1: $0,9 \%$. Bệnh mắt đái tháo đường có liên quan đến thời gian mắc bệnh đái tháo đường, giới tính, tăng huyết áp, mức đường huyết và bệnh thận mạn. Kết luận: Bệnh võng mạc có thể gây mù lòa. Việc phát hiện và điều trị sớm rất quan trọng. Để ngăn ngừa bệnh mắt đái tháo đường hoặc làm chậm tiến triển bệnh nên quản lý tốt đường huyết, huyết áp và cholesterol, và bỏ thuốc lá nếu có hút.

Chịu trách nhiệm chính: Châu Mỹ Chi

Ngày nhận bài: 02/11/2020

Ngày phản biện khoa học: 08/11/2020

Ngày duyệt bài: 11/12/2020

Email:chichaudr@gmail.com

Điện thoại: 0918046515

\section{1. ĐẠT VẤN ĐỀ}

Đái tháo đường (ĐTĐ) là bệnh rối loạn chuyển hoá glucid mạn tính.Bệnh ĐTĐ đang gia tăng trên toàn thế giới, kéo theo tỷ lệ các biến chứng cũng tăng theo, bao gồm cả biến chứng mắt. Tất cả bệnh nhân ĐTĐ đều có nguy cơ bị bệnh võng mạc ĐTĐ. Đái tháo đường cũng làm trầm trọng thêm các bệnh mắt khác như đục thủy tinh thể, glocom (tăng nhãn áp), mất khả năng tập trung thị lực và song thị.

Bệnh võng mạc ĐTÐ (VMĐTÐ - diabetic retinopathy) là một trong các biến chứng vi mạch của đái tháo đường. Theo WHO tỷ lệ 
bệnh VMĐTĐ chiếm từ 20\% đến 40\% người bị đái tháo đường, giới hạn này tuỳ theo từng quốc gia và khu vực. Thời gian mắc bệnh ĐTĐ và kiểm soát đường huyết là yếu tố nguy cơ chủ yếu của bệnh VMĐTĐ: ĐTĐ týp 1 sau 5 năm $25 \%$ bệnh nhân có bệnh VMĐTĐ, sau 10 năm là $60 \%$. ĐTĐ týp 2 sau 5 năm là $40 \%$ có bệnh võng mạc ĐTĐ và $2 \%$ có bệnh VMĐTĐ tăng sinh. Đây là nguyên nhân hàng đầu gây giảm thị lực và gây mù ở các nước phát triển. Bệnh nhân mắc bệnh ĐTĐ có nguy cơ mù loà tăng gấp 20-30 lần so với người cùng tuổi và giới.

Tại Việt Nam chưa có số liệu thống kê chính thức về tổn thương mắt trên bệnh nhân ĐTĐ. Những cuộc nghiên cứu nhỏ như Phạm Thị Hồng Hoa nghiên cứu trên 100 bệnh nhân ĐTĐ nằm điều trị tại khoa nội tiết bệnh viện Bạch Mai thấy tỷ lệ biến chứng mắt là 33,4\% trong đó tổn hại thị lực là $79 \%$.

Nếu được chẩn đoán muộn các biến chứng trên mắt bệnh nhân ĐTĐ sẽ dẫn đến giảm thị lực và có thể gây mù lòa, làm ảnh hưởng về kinh tế, tinh thần và chất lượng cuộc sống của bệnh nhân.Phát hiện sớm và điều trị kịp thời võng mạc đái tháo đường có thể làm chậm lại sự suy thoái của thị lực và giảm gánh nặng khi bị mất thị lực trên người bệnh, sự chăm sóc của người thân và toàn xã hội.

Bệnh võng mạc không tăng sinh (nonproliferative retinopathy) là giai đoạn sớm của bệnh, thường gặp ở người ĐTĐ. Các mao mạch phồng lên làm tắc nghẽn các mạch máu nuôi võng mạc. Chất dịch lỏng thấm qua thành mạch làm sưng điểm vàng (trung tâm võng mạc) gây phù hoàng điểm. Giai đoạn này, mắt bị mờ và có khả năng mất thị lực. Người bệnh ĐTĐphát hiện bệnh và điều trị sớm có cơ hội cao sẽ phục hồi thị lực.

Bệnh võng mạc tăng sinh (proliferative retinopathy) là giai đoạn trễ và nặng của tổn thương võng mạc.Các mạch máu nuôi võng mạc bị tắt nghẽn. Võng mạc tiết các chất kích thích gia tăng sự hình thành mạch máu mới. Những mạch máu này rất dễ vỡ, gây ra xuất huyết và bong võng mạc dẫn đến mất thị lực.

Phù hoàng điểm có thể xảy ra ở mọi giai đoạn của bệnh võng mạc. Cơ chế phù là tăng tính thấm thành mạch dẫn đến tích tụ dịch và lipoprotein trong võng mạc. Biểu hiện lâm sàng là các vùng xuất tiết màu vàng trong võng mạc. Bệnh thường không có triệu chứng gì trong thời kỳ đầu, do đó khám mắt định kỳ là cách duy nhất để xác định tổn thương trên võng mạc và từ đó có hành động thích hợp.Việc phát hiện, điều trị sớm các biến chứng mắt trên bệnh nhân ĐTĐ cùng với sự quản lý đường huyết tốt có vai trò quan trọng trong quá trình bảo tồn thị lực cho bệnh nhân.

Chúng tôi tiến hành nghiên cứu này với 2 mục tiêu sau:

1. Xác định tỉ lệ biến chứng mắt trên bệnh nhân đái tháo đường tại bệnh viện Đa khoa Trung tâm Tiền Giang

2. Mối liên quan giữa các biến chứng mắt trên bệnh nhân đái tháo đường và một số yếu tố nguy co.

\section{2. ĐỐI TƯợNG\&PHƯƠNG PHÁP NGHIÊN CÚU}

\section{1. Đối tượng nghiên cứu:}

Bệnh nhân đái tháo đường khám bệnh ngoại trútại Bệnh Viện Đa Khoa Trung tâm Tiền Giang.

\section{* Tiêu chuẩn chọn bệnh}

Tiêu chuẩn chẩn đoán đái tháo đường:Dựa vào tiêu chuẩn chẩn đoán củaADA năm 2017.

* Phân độ Bệnh mắt đái tháo đường

Phân loại quốc gia về Bệnh võng mạc đái tháo đường (VM ĐTĐ) sử dụng cho chương trình sàng lọc trền cộng đồng của Anh.

\begin{tabular}{|l|l|}
\hline \multicolumn{2}{|c|}{ Bệnh Võng mạc } \\
\hline R0 & Không có bệnh VM ĐTĐ \\
\hline R1 & Bệnh nền \\
\hline
\end{tabular}




\begin{tabular}{|c|c|}
\hline & $\begin{array}{l}\text { Vi phình mạch } \\
\text { Xuất huyết võng mạc } \\
\text { Quai tĩnh mạch } \\
\text { Xuất tiết cứng kèm theo các biểu hiện khác của VM ĐTĐ } \\
\text { Bất cứ xuất tiết bông nào kèm theo các biểu hiện khác của VM ĐTĐ }\end{array}$ \\
\hline $\mathrm{R} 2$ & $\begin{array}{l}\text { Tiền tăng sinh } \\
\text { Vòng tĩnh mạch } \\
\text { Tĩnh mạch đúp } \\
\text { Nhiều xuất huyết dạng vệt } \\
\text { Bất thường vi mạch trong võng mạc }\end{array}$ \\
\hline R3 & $\begin{array}{l}\text { Tăng sinh } \\
\text { R3s (Ổn định sau điều trị) } \\
\text { Màng xơ trước VM ồn định + laser VM chu biên rải rác (Cần có ảnh chụp tổn } \\
\text { thương sau khi xuất viện) } \\
\text { Tăng sinh xơ ổn định (gai thị hoặc bất cứ vị trí nào) + laser VM chu biên rải rác } \\
\text { Các triệu chứng của R2 ổn định + laser VM chu biên rải rác } \\
\text { R3a (Bệnh lý võng mạc tăng sinh hoạt động) } \\
\text { Tân mạch đĩa } \\
\text { Tân mạch rải rác nhiều nơi } \\
\text { Xuất huyết trước VM hoặc } \mathrm{DK} \text { mới } \\
\text { Màng xơ trước VM mới } \\
\text { BVM co kéo mới } \\
\text { Tái hoạt ở mắt giai đoạn R3s ổn định }\end{array}$ \\
\hline \multicolumn{2}{|r|}{ Bệnh hoàng điểm } \\
\hline M0 & $\begin{array}{l}\text { Bất cứ vi phình mạich hoặc xuất huyết trong phạm vị } 1 \text { đường kính gai quanh trung } \\
\text { tâm hoàng điểm nếu kèm theo thị lực tốt nhất ở mức } 6 / 12 \text { và nguyên nhân gây giảm } \\
\text { thị lực không phải do phù hoàng điểm ĐTĐ }\end{array}$ \\
\hline M1 & $\begin{array}{l}\text { Xuất tiết cứng trong phạm vi } 1 \text { đường kính gai từ trung tâm hoàng điểm } \\
\text { Đám xuất tiết cứng quanh hoàng điểm } \\
\text { (Đám xuất tiết cứng là tổn thương có kích thước lớn hơn hoặc bằng nửa diện tích gai } \\
\text { và nằm gọn trong khu vực hoàng điểm) } \\
\text { Dày võng mạc trong phạm vi } 1 \text { đường kính gai quanh trung tâm hoàng điểm (nếu có } \\
\text { hình nổi) } \\
\text { Bất cứ vi phình mạch hoặc xuất huyết trong phạm vi } 1 \text { đường kính gai quanh trung } \\
\text { tâm hoàng điểm chỉ khi kèm theo thị lực tốt nhất ở mức } 6 / 12 \text { hoặc kém hơn (nếu } \\
\text { không có hình nổi) }\end{array}$ \\
\hline P0 & Không có dấu vết của laser quang đông trước đó \\
\hline $\mathrm{P} 1$ & Laser khu trú/lưới ở khu vực hoàng điểm hoặc rải rác ở chu biên \\
\hline $\mathrm{U}$ & Hình ảnh không thể xếp hạng \\
\hline
\end{tabular}

2.2. Phương pháp nghiên cứu: Nghiên cứu cắt ngang, mô tả.

* Phương pháp tiến hành:

Chụp hình đáy mắt, đọc phân độ và lưu trữ dữ liệu của bệnh nhân trên phần mềm Spectra. Phân độ theo hệ thống NHS của Anh

* Phương pháp thu thập số liệu:

Hỏi và khám lâm sàng theo mẫu nghiên cứu đã thiết kế. 


\section{KÊT QUẢ NGHIÊN CỨU}

Qua nghiên cứu 111 bệnh nhân ĐTĐ chúng tôi có các kết quả sau:

3.1. Đặc điểm chung của đối tượng nghiên cứu

Bảng 3.1. Đặc điểm tuổi của đối tượng nghiên cứu

\begin{tabular}{|c|c|c|c|}
\hline Thông số & Trung bình $(\bar{X} \pm \mathrm{SD})$ & Nhỏ nhất & Lớn nhất \\
\hline Tuổi (năm) & $62,05 \pm 8,85$ & 40 & 86 \\
\hline
\end{tabular}

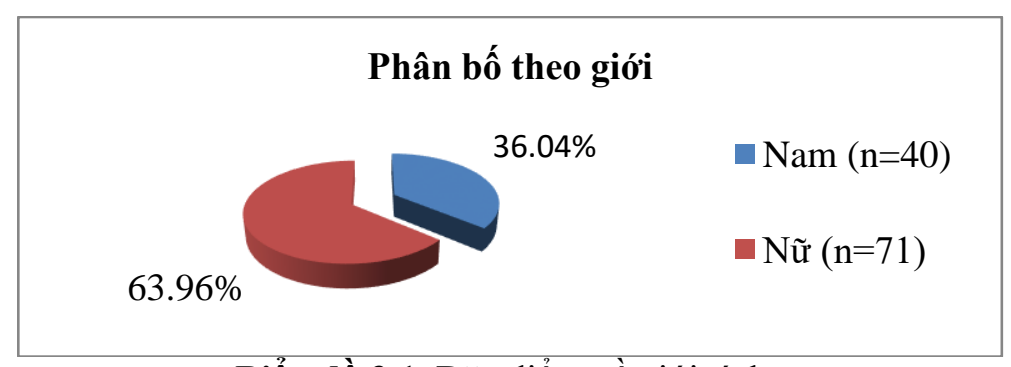

Biểu đồ 3.1. Đặc điểm về giới tính

Bảng 3.2. Thời gian phát hiện bệnh đái tháo đường

\begin{tabular}{|c|c|c|}
\hline Thời gian trung bình & Ngắn nhất & Dài nhất \\
\hline $8,52 \pm 6,34$ (năm) & 1 (năm) & 26 (năm) \\
\hline
\end{tabular}
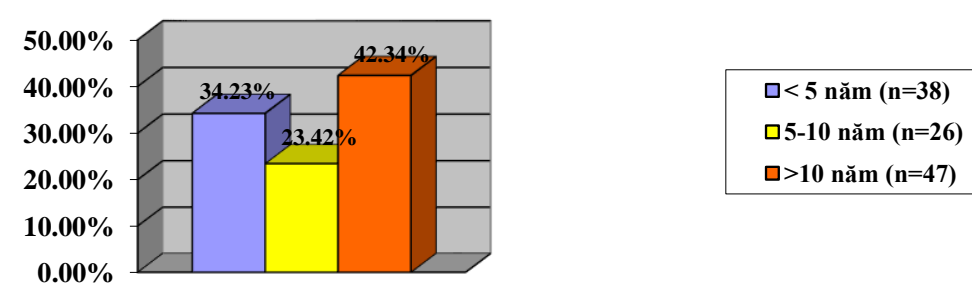

Thời gian phát hiện bệnh ĐTÐ

Biểu đồ 3.2. Thời gian phát hiện bệnh ĐTĐ

Bảng 3.3. Đặc điểm BMI

\begin{tabular}{|l|c|c|c|c|}
\hline \multicolumn{1}{|c|}{$\begin{array}{c}\text { BMI } \\
\left(\mathbf{k g} / \boldsymbol{m}^{\mathbf{2}}\right)\end{array}$} & $\begin{array}{c}\text { Số lượng } \\
\mathbf{N}(\boldsymbol{\%})\end{array}$ & $\begin{array}{c}\mathbf{N a m} \\
\mathbf{N}(\%)\end{array}$ & $\begin{array}{c}\text { Nũ } \\
\mathbf{N}(\%)\end{array}$ & \multirow{2}{*}{0,083} \\
\hline$<23(\mathrm{n}=43)$ & $43(38,74 \%)$ & $10(25 \%)$ & $33(46,48 \%)$ & \\
\hline $23-25(\mathrm{n}=20)$ & $20(18,02 \%$ & $9(22,5 \%)$ & $20(18,02 \%)$ & \\
\hline$\geq 25(\mathrm{n}=48)$ & $48(43,24 \%)$ & $21(52,5 \%)$ & $48(43,24 \%)$ & \\
\cline { 1 - 4 } Trung bình & $24,32 \pm 7,28$ & $25,86 \pm 0,61$ & $23,45 \pm 0,53$ & \\
\hline
\end{tabular}

- Thừa cân và béo phì $\left(\mathrm{BMI} \geq 23 \mathrm{~kg} / \mathrm{m}^{2}\right)$ chiếm $61,26 \%$ (béo phì chiếm $43,24 \%$ ), chưa có sự khác biệt rõ béo phì giữa nam và nữ.

Bảng 3.4. Đặc điểm HA tâm thu và tâm trương

\begin{tabular}{|l|c|c|c|c|}
\hline \multicolumn{1}{|c|}{$\begin{array}{c}\text { HA } \\
(\mathbf{m m H g})\end{array}$} & $\begin{array}{c}\text { Chung }(\mathbf{n = 1 1 1}) \\
(\bar{X} \mathbf{\pm} \mathbf{S D})\end{array}$ & $\begin{array}{c}\mathbf{N a m}(\mathbf{n}=\mathbf{4 0}) \\
(\bar{X} \mathbf{\pm} \mathbf{S D})\end{array}$ & $\begin{array}{c}\mathbf{N} \tilde{\mathbf{u}}(\mathbf{n}=\mathbf{7 1}) \\
(\bar{X} \mathbf{\pm} \mathbf{S D})\end{array}$ & $\mathbf{p}$ \\
\hline HA tâm thu & $123,06 \pm 11,73$ & $123,75 \pm 1,91$ & $122,67 \pm 0,93$ & 0,64 \\
\hline HA tâm trương & $76,75 \pm 7,28$ & $77,5 \pm 0,94$ & $76,33 \pm 0,94$ & 0,38 \\
\hline
\end{tabular}


HA tâm thu và HA tâm trương trung bình ở giới nam và nữ bệnh không có khác biệt $(\mathrm{p}>0,05)$.

Bảng 3.5. Đặc điểm về các biến chứng của đối tượng nghiên cứu

\begin{tabular}{|c|c|c|c|c|c|}
\hline \multicolumn{2}{|c|}{ Đặc điểm } & Nam & Nứ & Tống N (\%) & p \\
\hline \multirow[t]{2}{*}{ THA } & Có & 32 & 63 & $95(85,59 \%)$ & \multirow[t]{2}{*}{0,21} \\
\hline & Không & 8 & 8 & $16(14,41 \%)$ & \\
\hline \multirow[t]{2}{*}{ TMCT } & Có & 18 & 34 & $52(46,85 \%)$ & \multirow[t]{2}{*}{0,77} \\
\hline & Không & 22 & 37 & $59(53,15 \%)$ & \\
\hline \multirow[t]{2}{*}{ RLLP } & Có & 31 & 56 & $87(78,38 \%)$ & \multirow[t]{2}{*}{0,86} \\
\hline & Không & 9 & 15 & $24(21,62 \%)$ & \\
\hline \multirow[t]{2}{*}{ TBBMN } & Có & 2 & 5 & $7(6,31 \%)$ & \multirow[t]{2}{*}{0,67} \\
\hline & Không & 33 & 71 & $104(93,69 \%)$ & \\
\hline \multirow[t]{2}{*}{ Nhiễm trùng bàn chân } & Có & 1 & 3 & $4(3,6 \%)$ & 0,64 \\
\hline & Không & 39 & 68 & $107(96,4 \%)$ & \\
\hline \multirow[t]{2}{*}{ Bệnh thận mạn } & Có & 2 & 3 & $5(4,5 \%)$ & \multirow[t]{2}{*}{0,95} \\
\hline & Không & 38 & 68 & $106(95,5 \%)$ & \\
\hline
\end{tabular}

THA chiếm 85,59\% (95/111), không có sự khác biệt giữaTHA, thiếu máu cơ tim, rối loạn lipid, tai biến mạch máu não, nhiễm trùng chân, suy thận mạn theo giới $(\mathrm{p}>0,05)$.

Bảng 3.6. Đặc điểm glucose huyết tương và $\mathrm{HbA} 1 \mathrm{C}$

\begin{tabular}{|l|l|l|l|}
\hline \multicolumn{1}{|c|}{ Thông số } & Trung bình $(\bar{X} \pm \mathrm{SD})$ & \multicolumn{1}{c|}{ Số kiểm soát tốt } & \multicolumn{1}{c|}{ Số kiểm soát kém } \\
\hline Glucose $(\mathrm{mmol} / \mathrm{l})$ & $8,29 \pm 2,82$ & $48(56,76 \%)$ & $63(56,76)$ \\
\hline HbA1C $(\%)$ & $8,27 \pm 1,97$ & $29(26,13 \%)$ & $82(73,87)$ \\
\hline
\end{tabular}

Đa số bệnh nhân ĐTĐ có tỉ lệ kiểm soát glucose huyết tương và HbA1C kém $(>50 \%)$. Tỉ lệ kiểm soát tốt glucose máu chiếm $56,76 \%$, HbA1C chiếm $26,13 \%$.

Bảng 3.7. Đặc điểm chung về lipid máu ở nhóm ĐTĐ

\begin{tabular}{|c|c|c|c|c|}
\hline Thông số (mmol/l) & $\begin{array}{c}\text { Nam (n=25) } \\
(\bar{X} \pm \mathrm{SD})\end{array}$ & $\begin{array}{c}\mathbf{N} \tilde{\mathbf{u}}(\mathbf{n}=\mathbf{5 6}) \\
(\bar{X} \pm \mathrm{SD})\end{array}$ & $\begin{array}{c}\text { Chung }(\mathbf{n = 1 1 1}) \\
(\bar{X} \pm \mathrm{SD})\end{array}$ & $\mathbf{p}$ \\
\hline Cholesterol & $4,43 \pm 0,14$ & $4,89 \pm 0,17$ & $4,73 \pm 1,31$ & 0,04 \\
\hline Triglycerid & $2,52 \pm 0,26$ & $2,40 \pm 0,19$ & $2,44 \pm 1,67$ & 0,71 \\
\hline HDL-C & $1,05 \pm 0,37$ & $1,16 \pm 0,24$ & $1,12 \pm 0,25$ & 0,04 \\
\hline LDL-C & $2,82 \pm 0,11$ & $2,98 \pm 0,12$ & $2,92 \pm 0,95$ & 0,35 \\
\hline
\end{tabular}

Cholestrerol ở nữ cao hơn nam, sự khác biệt có ý nghĩa thống kê.

3.2. Đặc điểm về bệnh lý mắt của đối tượng nghiên cứu

Bảng 3.8. Tỉ lệ biến chứng mắt theo giới

\begin{tabular}{|l|l|l|l|l|}
\hline Mắt & Số lượng (\%) & Nam N(\%) & NữN(\%) & $\mathbf{p}$ \\
\hline Bình thường & $75(67,57 \%)$ & $33(82,5 \%)$ & $42(59,15 \%)$ & \multirow{2}{*}{0,01} \\
\cline { 1 - 4 } & $36(32,43 \%)$ & $7(17,5 \%)$ & $29(40,85 \%)$ & \\
\hline
\end{tabular}

Có sự khác biệt về bệnh lý mắt trên bệnh nhân đái tháo đường theo giới. 
Bảng 3.9. Đặc điểm biến chứng mắt

\begin{tabular}{|l|l|c|c|}
\hline \multicolumn{2}{|c|}{ Đặc điểm biến chứng mắt } & Số lượng $\mathbf{~}$ & Tỷ lệ \% \\
\hline \multirow{4}{*}{ Bình thường } & Tổng & 75 & $67,57 \%$ \\
\hline \multirow{5}{*}{ Bệnh lý } & DTTT & 36 & $32,43 \%$ \\
\cline { 2 - 4 } & R1M0+ĐTTT & 10 & $9,01 \%$ \\
\cline { 2 - 4 } & R1M0 & 3 & $2,7 \%$ \\
\cline { 2 - 4 } & R1M1 & 13 & $11,71 \%$ \\
\cline { 2 - 4 } & R2M0 & 1 & $2,7 \%$ \\
\cline { 2 - 4 } & R2M1 & 2 & $0,9 \%$ \\
\cline { 2 - 4 } & R3M1 & 1 & $0,9 \%$ \\
\hline
\end{tabular}

Biến chứng mắt 36/111 trường hợp chiếm tỉ lệ 32,43\%. Trong đó, đục thủy tinh thể (ĐTTT) có 13 trường hợp, chiếm 11,71\%; Bệnh võng mạc đái tháo đường( $\mathrm{R} 1, \mathrm{R} 2, \mathrm{R} 3) 26$ trường hợp chiếm 23,42\%. Giai đoạn nền (R1) 19 trường hợp chiếm tỉ lệ17,12\% ((trong đó có 3 trường hợp phối hợp đục thủy tinh thể và có 3 trường hợp tồn thương hoàng điểm). Giai đoạn tiền tăng sinh (R2) 3 trường hợp chiếm tỉ lệ $2,7 \%$ (có 2 trường hợp tổn thương hoàng điểm). Giai đoạn tăng $\sinh (\mathrm{R} 3)$ và có tồn thương hoàng điểm là 1 trường hợp chiếm tỉ lệ $0,9 \%$.

\subsection{Mối liên quanbệnh lý mắt với các yếu tố nguy cơ khác}

Bảng 3.10. Mối liên quan giữa mắt với các yếu tố định tính

\begin{tabular}{|c|c|c|c|c|}
\hline \multicolumn{2}{|c|}{ Đặc điểm } & Mắt bình thường & Mắt bất thường & $\mathbf{p}$ \\
\hline & Có & $60(80 \%)$ & $35(97,22 \%)$ & \multirow{2}{*}{0,01} \\
\hline & Không & $15(20 \%)$ & $1(2,78 \%)$ & \\
\hline \multirow{2}{*}{ Kiểmsoát glycemie } & Tốt & $31(41,33 \%)$ & $17(47,22 \%)$ & \multirow{2}{*}{0,55} \\
\hline & Không tốt & $44(58,67 \%)$ & $19(52,78 \%)$ & \\
\hline \multirow{2}{*}{ Kiểm soát $\mathrm{HbA1C}$} & Tốt & $23(30,67 \%)$ & $6(16,67 \%)$ & \multirow{2}{*}{0,11} \\
\hline & Không tốt & $52(69,33 \%)$ & $30(83,33 \%)$ & \\
\hline \multirow{2}{*}{ TMCT } & Có & $32(42,67 \%)$ & $20(55,56 \%)$ & \multirow{2}{*}{0,20} \\
\hline & Không & $43(57,33 \%)$ & $16(44,44 \%)$ & \\
\hline \multirow{2}{*}{ RLLP } & Có & $55(73,33 \%)$ & $32(88,89 \%)$ & \multirow{2}{*}{0,06} \\
\hline & Không & $20(26,67 \%)$ & $4(11,11 \%)$ & \\
\hline \multirow{2}{*}{ TBMMN } & Có & $5(6,67 \%)$ & $2(5,56 \%)$ & \multirow{2}{*}{0,82} \\
\hline & Không & $70(93,33 \%)$ & $34(94,44 \%)$ & \\
\hline \multirow{2}{*}{ Nhiễm trùng chân } & Có & $2(2,67 \%)$ & $2(5,56 \%)$ & \multirow{2}{*}{0,44} \\
\hline & Không & $73(97,33 \%)$ & $34(94,44 \%)$ & \\
\hline \multirow{2}{*}{ Bệnh thận mạn } & Có & $0(0 \%)$ & $5(13,89 \%)$ & \multirow{2}{*}{0,00} \\
\hline & Không & $75(100 \%)$ & $31(86,11 \%)$ & \\
\hline
\end{tabular}

Bệnh mắt đái tháo đường có liên quan đến tình trạng tăng huyết áp, bệnh thận mạn có ý nghĩa thống kê $(\mathrm{p}<0,05)$. 
Bảng 3.11. Liên quan giữa bệnh lý mắt với tuổi, thời gian phát hiện bệnh, $H A$, đường huyết và lipid máu

\begin{tabular}{|l|c|c|c|}
\hline \multicolumn{1}{|c|}{ Thông số } & $\begin{array}{c}\text { Không biến chứng mắt } \\
(\bar{X} \pm \mathbf{S D})\end{array}$ & $\begin{array}{c}\text { Có biến chứng mắt } \\
(\bar{X} \pm \mathbf{S D})\end{array}$ & $\mathbf{p}$ \\
\hline Tuổi & $61,56 \pm 8,97$ & $64,47 \pm 8,97$ & 0,11 \\
\hline $\begin{array}{l}\text { Thời gian phát hiện } \\
\text { bệnh ĐTĐ }\end{array}$ & $7,70 \pm 6,36$ & $10,22 \pm 6,04$ & 0,04 \\
\hline HA TThu & $122,4 \pm 1,31$ & $124,44 \pm 2,08$ & 0,39 \\
\hline HA TTr & $75,73 \pm 0,81$ & $78,88 \pm 1,24$ & 0,03 \\
\hline Glucose & $7,86 \pm 0,27$ & $9,17 \pm 0,57$ & 0,04 \\
\hline HbA1C & $8,08 \pm 0,24$ & $8,67 \pm 0,27$ & 0,13 \\
\hline TG & $2,41 \pm 0,19$ & $2,52 \pm 0,26$ & 0,72 \\
\hline Cho & $4,71 \pm 0,15$ & $4,77 \pm 0,21$ & 0,79 \\
\hline HDL & $1,11 \pm 0,29$ & $1,13 \pm 0,04$ & 0,74 \\
\hline LDL & $2,91 \pm 1,01$ & $2,94 \pm 0,85$ & 0,89 \\
\hline
\end{tabular}

Bệnh mắt đái tháo đường có liên quan đến thời gian phát hiện bệnh, huyết áp tâm trương và đường huyết, sự khác biệt có ý nghĩa $(\mathrm{p}<0,05)$.

\section{BÀN LUẬN}

4.1. Các đặc điểm chung của đối tượng nghiên cứu

4.1.1. Về tuổi, giới, thòi gian mắc bệnh đái tháo đường, chỉ số khối cơ thể

Tuổi trung bình trong nghiên cứu của chúng tôi là $62,05 \pm 8,85$ tuổi tương tự các nghiên cứu khác về ĐTĐ như của Trần Ngọc Hoàng và Nguyễn Thị Bích Đào tuổi trung bình $62,2 \pm 11,0 \pm 9,27$ tuổi.

Mặc dù các số liệu thống kê gần đây cho thấy đái tháo đường ngày càng trẻ hóa, nhưng tuổi cũng đóng vai trò quan trọng trong phát triển ĐTĐ týp 2 có lẽ do tuổi càng cao thì sự tiêu hủy tế bào beta tăng, khả năng tái sinh tế bào bêta giảm do lão hóa kèm theo sự đề kháng insulin kết hợp với béo phì và lối sống tĩnh tại ở người cao tuổi.

Trong nghiên cứu chúng tôi, nữ chiếm ưu thế hơn nam (63,96\% so với 36,04\% ). Nhìn chung, các nghiên cứu ở bệnh nhân ĐTĐ có ghi nhận nữ chiếm tỉ lệ cao hơn nam.

Thời gian trung bình là $8,52 \pm 6,34$ năm, dưới 5 năm chiếm $34,23 \%$, từ $5-10$ năm chiếm $23,42 \%$, trên 10 năm chiếm 42,34\%. Thời gian mắc bệnh lâu dài góp phần làm tăng diễn tiến các biến chứng của bệnh, tăng nguyên nhân nằm viện của người bệnh.

Về chỉ số khối cơ thể: BMI trung bình là $24,75 \pm 7,28 \mathrm{~kg} / \mathrm{m}^{2}$. Không có sự khác biệt BMI ở nam và nữ $(\mathrm{p}>0,05)$. Tỉ lệ thừa cân và béo phì chiếm $61,26 \%$. Béo phì chiếm $43,24 \%$. Béo phì cũng là yếu tố nguy cơ gây ra nhiều bệnh về rối loạn chuyển hóa nhưng đặc biệt là các bệnh đái tháo đường type 2 , tăng huyết áp, bệnh tim mạch.

4.1.2. Đặc điểm về các biến chúng: Tănghuyết áp, thiếu máu co tim, rối loạn lipid máu, tai biến mạch máu não, nhiễm trùng chân, bệnh thận mạn

Nghiên cứu của chúng tôi THA chiếm tỉ lệ cao $85,59 \%$. Nghiên cứu của chúng tôi phù hợp với tác giả Norman, tỉ lệ THA ở bệnh nhân ĐTĐ trên $70 \%$. Trong nghiên cứu UKPDS, các tác giả ghi nhận kiểm soát tốt huyết áp giúp giảm tần suất mới mắc và ngăn sự tiến triển của bệnh võng mạc ở người bệnh đái tháo đường týp 2.

Thiếu máu cơ tim: Trong nghiên cứu ghi nhận bệnh nhân có tiền sử thiếu máu cơ tim và đang điều trị chiếm tỉ lệ 46,85\%.

Rối loạn lipid máu: Tỉ lệ bệnh nhân có rối 
loạn lipid máu chiếm 78,38\%

Trong nghiên cứu ghi nhận có 7 trường hợp tiền sử đã trải qua tai biến mạch máu não, chiếm tỉ lệ $6,31 \%$

Tiền sử đã điều trị nhiễm trùng bàn chân có 4 trường hợp, chiếm tỉ lệ $3,6 \%$.

Bệnh thận mạn đã được chẩn đoán trước đó là 5 trường hợp, chiếm tỉ lệ $4,5 \%$

\subsection{3. Đặc điểm về các chi số đường huyết, lipid máu}

Glucose máuvà $\mathrm{HbA} 1 \mathrm{C}$ : Giá trị đường huyết trung bình trong nghiên cứu của chúng tôi là $8,29 \pm 2,82 \mathrm{mmol} / 1$, tỉ lệ bệnh nhân kiểm soát đường huyết tốt là $56,76 \%$, chưa đạt mục tiêu là $56,76 \%$. Giá trị $\mathrm{HbA} 1 \mathrm{C}$ trung bình là $8,27 \pm 1,97 \%$, tỉ lệ kiểm soát $\mathrm{HbA} 1 \mathrm{C}$ tốt là $26,13 \%$, chưa đạt mục tiêu là $73,87 \%$. Theo ADA 2014, HbA1C đạt mục tiêu khi $\mathrm{HbA} 1 \mathrm{C}<7 \%$ thì kết quả nghiên cứu của chúng tôi cho thấy phần lớn chưa đạt được mục tiêu điều trị như khuyến cáo.Kết quả $\mathrm{HbA} 1 \mathrm{C}$ cũng tương đương khi so với quan sát của một số tác giả trong và ngoài nước như của Nguyễn Bá Việt là $8,77 \pm 2,08 \%$, của Ypfei Mo là $8,3 \pm 1,7 \%$.

Đặc điểm về nồng độ trung bình của cholesterol là $4,73 \pm 1,31 \mathrm{mmol} / \mathrm{l}$; triglyceride là $2,44 \pm 1,67 \mathrm{mmol} / 1$; HDL-cholesterol là $1,12 \pm 0,25 \mathrm{mmol} / 1$ và của LDL-cholesterol là $2,92 \pm 0,95 \mathrm{mmol} / 1$. Nồng độ cholesterol có sự khác biệt đáng kể giữa 2 giới nam và nữ. Trong nghiên cứu ghi nhận nồng độ trung bình của lipid máu nhìn chung không cao, điều này cũng phù hợp vì đa số bệnh nhân (78,38\%) đã được chẩn đoán rối loạn lipid máu và đã được tiến hành điều trị.

\subsection{Mô tả các biến chứng mắt}

BệnhVM ĐTĐ tiến triển thầm lặng theo thời gian nên dù bệnh có thể gây tàn phá thị giác nhưng thị lực ban đầu vẫn còn tốt.

Nghiên cứu của chúng tôi ghi nhận có 36 trường hợp có bệnh lý mắt bao gồm đục thủy tinh thể chiếm tỉ lệ $32,57 \%$ trong đó nam $6,31 \%$, nữ chiếm $26,12 \%$. Bệnh võng mạc đái tháo đường 26 trường hợp chiếm $23,42 \%$. Giai đoạn nền 19 trường hợp chiếm tỉ lệ 17,12\% (trong đó có phối hợp 3 trường hợp đục thủy tinh thể và 3 trường hợp tổn thương hoàng điểm). Giai đoạn tiền tăng sinh 3 trường hợp chiếm tỉ lệ $2,7 \%$ (có 2 trường hợp tổn thương hoàng điểm). Giai đoạn tăng sinh và có tổn thương hoàng điểm là 1 trường hợp chiếm tỉ lệ $0,9 \%$.

Theo nghiên cứu của Trần Đỗ Lan Phươngtỷ lệ biến chứng võng mạc đái tháo đường là 24,1\%. Tác giả Nguyễn Thị Thu Thủy và cộng sự ghi nhận bệnh võng mạc ĐTĐ trong nghiên cứu này là $28,7 \%$. Theo tác giả King và cộng sự thì bệnh lý võng mạc đái tháo đường là $40 \%$, theo các $\mathrm{y}$ văn ghi nhận khoảng $10 \%$ số bệnh nhân ĐTĐ ở Anh có biến chứng mắt, tác giả Sven-Erik Bursell và cộng sự thì ghi nhận bệnh võng mạc không tăng sinh chiếm $17,7 \%$ còn bệnh lý võng mạc tăng sinh chiếm $2,3 \%$.

Như vậy, kết quả nghiên cứu của chúng tôi cũng tương tự như của các tác giả trong nước và tương tự của tác giảSven Erik Bursell ở Ấn Độ.

\subsection{Mối liên quan giữa bệnh lý võng mạc đái tháo đường với các yếu tố trong nghiên cứu.}

Trong nghiên cứu của chúng tôi ghi nhận bệnh mắt ở bệnh nhân đái tháo đường liên quan với thời gian phát hiện bệnh, liên quan đến giới tính, liên quan với huyết áp nhất là huyết áp tâm trương, liên quan đến đường huyết và với bệnh thận mạn.

Nghiên cứu của tác giả Nguyễn Thị Thu Thủy cũng ghi nhận biến chứng mắt ở bệnh nhân ĐTĐ cũng liên quan đến giới tính, thời gian phát hiện bệnh ĐTĐ và tăng huyết áp như trong nghiên cứu của chúng tôi.

Trong nghiên cứu UKPDS cho thấy kiểm soát đường huyết tích cực giảm được $25 \%$ nguy cơ biến chứng mạch máu nhỏ bao gồm bệnh võng mạc, bệnh thận và bệnh lý thần kinh đái tháo đường.

Các nghiên cứu DCCT (Diabetes Control and Complications Trial) ở người bệnh đái tháo đường týp 1 và UKPDS (United Kingdom Prospective Diabetes Study) ở người bệnh đái tháo đường týp 2 cho thấy kiểm soát tốt đường huyết giúp giảm tần suất mới mắc và ngăn sự tiến triển của bệnh võng mạc. 
ACCORD EYE được thiết kế nhằm đánh giá ảnh hưởng trên sự tiến triển bệnh võng mạc ở người bệnh đái tháo đường týp 2 của 3 chiến lược điều trị: kiểm soát đường huyết tích cực, phối hợp thuốc hạ lipid máu và kiểm soát huyết áp tích cực. Ảnh hưởng của kiểm soát đường huyết tích cực: $\mathrm{HbA} 1 \mathrm{c}$ trung vị ban đầu là $8,0 \%$, sau 1 năm giảm xuống $6,4 \%$ ở nhóm kiểm soát đường huyết tích cực và $7,5 \%$ ở nhóm kiểm soát đường huyết qui ước (khác biệt rất có ý nghĩa với $\mathrm{p}<0,001$ ). Sau 4 năm, tỉ lệ tiến triển của bệnh võng mạc là $7,3 \%$ ở nhóm kiểm soát đường huyết tích cực và $10,4 \%$ ở nhóm kiểm soát đường huyết qui ước $(\mathrm{OR}$ hiệu chỉnh $=0,67 ; \mathrm{p}=0,003)$. Tỉ lệ mất thị giác mức độ vừa là $16,3 \%$ ở nhóm kiểm soát đường huyết tích cực và $16,7 \%$ ở nhóm kiểm soát đường huyết qui ước ( $\mathrm{OR}$ hiệu chỉnh $=0,95 ; p=0,56$ ).

\section{KẾT LUẬN}

Qua nghiên cứu 111 bệnh nhân ĐTĐ, chúng tôi có các kết luận sau:

1. Tỉ lệ biến chứng mắt trên bệnh nhân đái tháo đường tại bệnh viện Đa khoa Trung tâm Tiền Giang là $32,43 \%$. Xét theo giới tính: nữ có biến chứng mắt chiếm tỉ lệ $40,85 \%$, nam là $17,5 \%$.

Bệnh võng mạc đái tháo đường chiếm $23,42 \%$ : giai đoạn nền là $17,11 \%$; giai đoạn tiền tăng sinh là $2,7 \%$; giai đoạn tăng sinh là $0,9 \%$. Đục thủy tinh thể là $11.71 \%$.

2. Biến chứng mắt trên bệnh nhân đái tháo đường có liên quan đến giới tính, thời gian mắc bệnh đái tháo đường, huyết áp, bệnh thận mạn, đường huyết, cholesterol.

\section{KHUYẾN NGH!}

BệnhVM ĐTĐ là một nguyên nhân gây mù có thể phòng tránh. Phòng ngừa tốt nhất là phát hiện sớm. Sàng lọc biến chứng mắt do ĐTĐ cần được quan tâm hơn. Việc quản lý đái tháo đường và khám mắt để phát hiện tổn thương sớm có thể giúp việc ngăn ngừa quá trình suy giảm thị lực. Để giữ thị lực tốt cần tối ưu hóa các yếu tố sau: đường huyết, huyết áp, kiểm soát lượng mỡ trong máu, khám mắt định kỳ và chuyển tuyến chữa trị kịp thời.

\section{TÀI LIÊU THAM KHẢO}

1. Nguyễn Quốc Dân (2009), Nghiên cứu các biến chứng mắt trên bệnh nhân đái tháo đường tại tỉnh Bắc Ninh, luận văn thác sĩ y học, tr 5-20.

2. Nguyễn Thị Thu Thủy, Trần Anh Tuấn, Diệp Thanh Bình (2009), Khảo sát biến chứng tại mắt trên bệnh ĐTĐ đang điều trị tại bệnh viện Đại Học Y Dược TP. HCM. Y Học TP. Hồ Chí Minh, Vol. 13 tr $86-91$.

3. Anjali R. Shah,Thomas W. Gardner (2017), Diabetic retinopathy: research to clinical practice, Clin Diabetes Endocrinol., pp 3-9.

4. Bursell S.K, Fonda S.J, Lewis D.g, Horton M.B (2018), Prevalence of diabetic retinopathy and diabetic macular dema in a primary care-based teleophthalmology program for American Indians and Alaskan Natives, PLoS ONE 13(6): e0198551. https://doi.org/10.1371/journal.pone.0198 551, pp 1-9

5. Chi-Juei Jeng, Yi-Ting Hsieh, ChungMay Yang, et al. (2018), Diabetic Retinopathy in Patients with Dyslipidemia:Development and Progression, Ophthalmology Retina Volume 2, Number 1, pp 40-45.

6. International Council of Ophthalmology (2017), ICO Guidelines for Diabetic Eye Care, pp 50-60.

7. International Diabetes Federation and The Fred Hollows Foundation, Diabetes Eye Health (2015), A guide for health care professionals. Brussels, Belgium: International Diabetes Federation, pp 30-45. 